\title{
ON THE PHOTOSENSITIVE SUBSTANCE IN THE CHICKEN RETINA
}

\author{
ICHINOJO TANABE* \\ Department of. Physiology, Osaka City Medical School, Osaka
}

As to a photosensitive substance in the cone the informations so far obtained are neither complete nor accurate. The first attempt to identify a cone substance in the retina was made by v. Studnitz (11) who bleached the isolated retina and measured the changes in light absorption at different wave-lengths. On the basis of his results v. Studnitz claimed to have demonstrated the presence of a photosensitive cone substance. However, little attention was paid to the contraction of the inner cone segments caused by illumination as well as to the coloured oil globules in the inner segments of the cones, and so he failed in this experiment to convince most workers in the sphere of retinal photochemistry. Later he (12) succeded in extracting an ether-soluble substance from the frog retina which had a maximum absorption at about $560 \mathrm{~m} \mu$. In repeating his experiments on the tortoise and the snake, he (13) found a similar absorption in the former and three absorption maxima at 468, 560 and $650 \mathrm{~m} \mu$ in the latter. Hanström (4) described an ether-soluble substance with two maxima at 460 and $590 \mathrm{~m} \mu$ obtained from the macular region of the monkey retina. Chase (1) prepared a water-soluble extract from the frog retina and obtained an absorption curve with a maximum at $530 \mathrm{~m} \mu$. Wald (15) announced the extraction from the chicken retina, of a water-soluble cone substance with a maximum absorption at $575 \mathrm{~m} \mu$. Hosoya, Okita and Akune (7) extracted a water-soluble cone substance from the tortoise retina in dim blue-violet light with maximum absorptions at 460, 570 and $670 \mathrm{~m} \mu$.

Examining photometrically a substance extracted from the chicken retina the author obtained results, not necessarily agreeing with those so far reported by other authors.

Experimental procedures on the retina have to be carried out in light which is not effective on the photosensitive substance in the retina. It may be supposed that the spectral sensitivity of the chicken differs from that of the human being. Hess (6) examined in detail the light and colour senses of various vertebrates. In his experiment a remarkable characteristic was found in the fowl, representing an avian tribe. So far as the spectrum was concerned, the bird showed most marked sensitivity to orange with a gradual decrease towards the violet, i.e., in the region of green the fowl needed an intensity of light 20 to 30 times and in the region of blue 200 times that of man. According to Hosoya (8), in his experiments with the bird, the gradual decrease in sensitivity towards the

Received for publication June 23, 1952.

* 田辺市之亟 
shorter wave-length terminated in nil before it reached the violet. Hess considered this phenomena as due to the absorption of part of the shorter wavelengths by the coloured oil globules in the inner segments of the cones. v. Studnitz and Busch (14) measured the spectral absorption of these globules and found that lights of wave-lengths shorter than $550 \mathrm{~m} \mu$ were almost absorbed by them.

\section{EXPERIMENTAL}

The animals employed were newly hatched white leghorn male chickens. They were fed in a chamber at $30^{\circ} \mathrm{C}$ with rice, vegetables and water. After 20 days 20 chickens were kept in the dark for three to four hours and their heads were then cut off in dim blue-violet light $(<470 \mathrm{~m} \mu)$, in which the chicken had been left perfectly blind.* Then the eyeballs were enucleated and excised in the dark and the retinae were isolated in Ringer's solution in the blue-violet light, transmitted through filters from a white lamp $(20 \mathrm{~W}, 100 \mathrm{~V})$. The filters used were $20 \%$ copper sulphate solutions in a glass chamber $5 \mathrm{~cm}$. thick, and three pieces of cobalt glass $0.25 \mathrm{~cm}$. thick. Thus all rays longer than $470 \mathrm{~m} \mu$ were checked.

In order to extract the visual purple, digitonin, bile salts and other celldestructive drugs are usually employed. To the cone substance these drugs may also be applicable. On the chicken retina Wald used digitonin, on the tortoise retina Hosoya used sodium cholate. When the chicken retina is immersed in $2 \%$ sodium glycocholate $\left(p_{\mathrm{H}} 7.2\right.$ ) for about half a day and examined microspically, the cone cells become swollen and destroyed in a disorderly fashion. The absorption of sodium glycocholate in the visible range of the spectrum is equal to that of distilled water.

The retinal substance was extracted with $2 \%$ sodium glycocholate solution in an ice chamber $\left(5^{\circ} \mathrm{C}\right.$.), light being kept away, for fifteen to sixteen hours, then was centrifugalized in order to obtain the supernatant fluid which was a transparent reddish yellow. The extract was put in a cuvette $(5 \mathrm{cc}$. in volume, $1 \mathrm{~cm}$. in thickness) in a camera of the measuring apparatus.

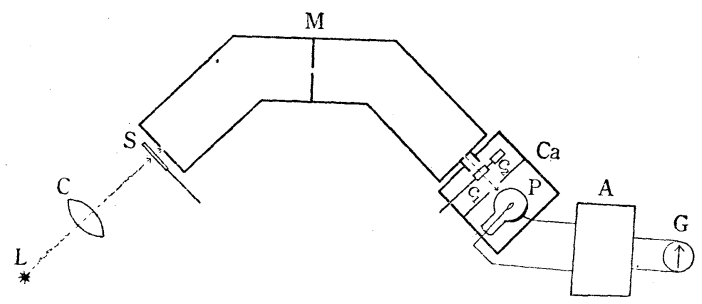

FIG. 1. Diagrammatic representation of experimental arrangement for measuring of spectral absorption of extract.

$L:$ light source, $C:$ condensing lens, $S:$ shutter, $M:$ double monochromator, $C a:$ camera, $c_{1}, c_{2}$ : cuvette for sample and control, $P$ : secium phototube, $A:$ D.C. amplifier, $G:$ galvanometer.

* Hosoya first introduced the dim blue-violet light in his experiment on the tortoise retina. 
The extinction coefficient of the extract was measured photoelectrically in the range 400 to $700 \mathrm{~m} \mu$, employing a double monochromator, from which each ray of width $1 \mathrm{~m} \mu$ could be obtained. The intensity of monochromatic rays used in measurement was too weak to effect the extract. The light transmitted through the extract was received in a secium phototube and the photoelectric current was amplified by a D.C. amplifier and measured by a galvanometer. The measuring apparatus is illustrated in fig. 1. After the measurement the extract was illuminated for twenty minutes with a white lamp $(200 \mathrm{~W}, 100 \mathrm{~V})$ from a distance of $30 \mathrm{~cm}$., resulting in the loss of the red tone. The heat radiation from the light source was absorbed by water contained in a glass flask in thickness of $5 \mathrm{~cm}$., placed between the lamp and the extract. The spectral absorption was measured as before. Difference between both extinctions was interpreted as the photosensitivity of the extract.

In another series the experimental animals were kept in a chamber of about 800 Lux during the whole feeding period, with two white lamps (each $100 \mathrm{~W}$, $100 \mathrm{~V}$ ) in the chamber. They were fed with the same diets as in the previous case. Results obtained from them were compared with that of the previous series.

\section{RESULTS}

As seen in fig. 2 the spectral absorption of the extract differs very much from that of the visual purple, in which the absorption in the regions of shorter wave-lengths is marked and in the regions of longer wave-lengths slight, while the maximal absorption of the visual purple is seen in the middle wave-lengths. Accordingly, the absorption curve of the extract indicates a gradually falling curve from the violet end to the red end of the spectrum. In the absorption curve there are marked high humps at 420,450 and $480 \mathrm{~m} \mu$, and at 540,570 and $620 \mathrm{~m} \mu$ there are less marked ones.

The changes in absorption of the extract after bleaching with the white lamp also differ from that in the case of the visual purple, as

FIG. 2. Spectral absorption curve of the retinal extract from the chicken, bred in ordinary indoor brightness, 20th day after hatching.

Curve I : before bleaching, Curve II : after bleaching with a white lamp (200 W, $100 \mathrm{~V})$ for 20 minutes. Curve III : absorption difference caused by bleaching.

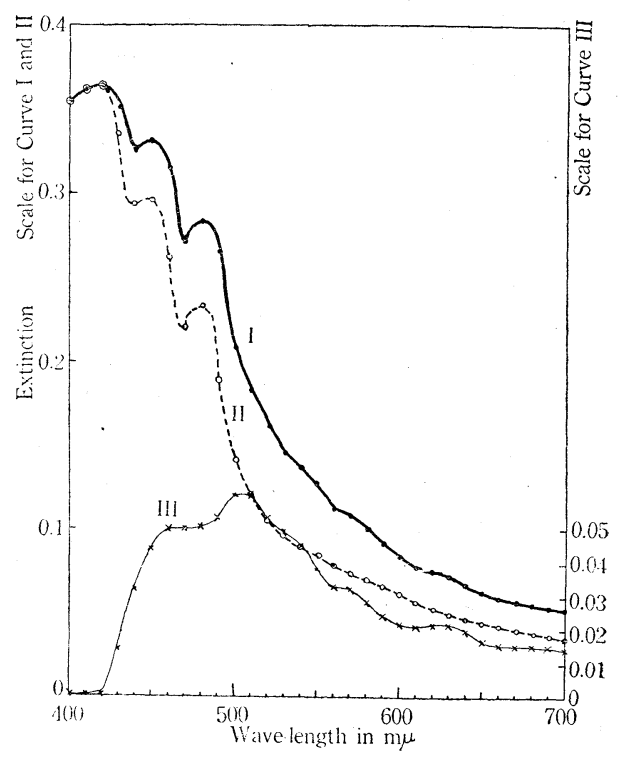


the changes are noticeable in all parts of the spectrum except in the violet end of the spectrum. At the violet end at waves shorter than $420 \mathrm{~m} \mu$ there is no difference due to the bleaching. The absorption difference brought about by the bleaching of the extract, when precisely examined, is found to be not uniform in all parts of the spectrum, that is, the differences are greater in five regions than in others. In curve III, indicating the absorption difference caused by bleaching, there are five maxima in blue $(460 \mathrm{~m} \mu)$, blue-green $(510 \mathrm{~m} \mu)$, green $(540 \mathrm{~m} \mu)$, yellow $(570 \mathrm{~m} \mu)$ and red $(630 \mathrm{~m} \mu)$, where the maximum in bluegreen is the most prominent.

These findings undergo some alteration in animals which were fed under continuous illumination. The spectral absorption of their retinal extract and its changes after bleaching of the extract are illustrated in fig. 3. The difference in spectrum, in this case, is seen to have diminished in all spectral regions; particularly, the maximum at $510 \mathrm{~m} \mu$, which was prominent in animals fed in ordinary indoor brightness, is remarkably depressed here. But the other four absorption maxima at other parts of the spectrum undergo no mentionable alterations.

FIG. 3. Spectral absorption curve of the retinal extract from the chicken, bred in brightness of $800 \mathrm{Lux}, 20$ th day after hatching.

Curve I : before bleaching, Curve II : after bleaching with a white lamp (200 $\mathrm{W}, 100 \mathrm{~V}$ ) for 20 minutes. Curve III : $a b-$ sorption difference caused by bleaching.

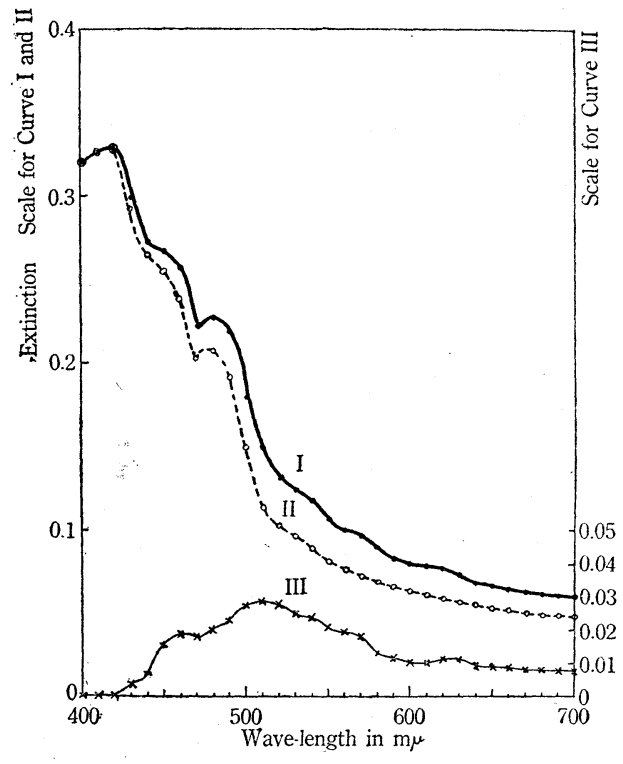

\section{DISCUSSION}

\section{Absorption maxima at 460,540, 570 and $630 \mathrm{m \mu}$}

In the cone substance of the chicken retina found by Wald, the maximal absorption was at $575 \mathrm{~m} \mu$. In electrophysiological researches Granit and others (3) obtained several modulator curves, whose maxima were at 460, 530, 580 and $610 \mathrm{~m} \mu$, particularly at $560 \mathrm{~m} \mu$ in the chicken retina. So far three retinal pigments have been known; visual purple (crest wave-length $=502 \mathrm{~m} \mu$ ), visual violet $(533 \mathrm{~m} \mu)$ and visual blue $(570 \mathrm{~m} \mu)$. Recently Dartnall (2) has found three other new pigments in the tench retina, visual blue-green (crest wavelength $=608 \mathrm{~m} \mu)$, visual red $(475 \mathrm{~m} \mu)$ and visual yellow No. $2(407 \mathrm{~m} \mu)$. Hartridge (5) has suggested that additional pigments which would complete the series would be ; visual green $(657 \mathrm{~m} \mu)$, visual orange $(450 \mathrm{~m} \mu)$, visual yellow No. 1 $(427 \mathrm{~m} \mu)$ and visual yellow No. $3(389 \mathrm{~m} \mu)$. 
It cannot be denied that there may be several parts in the spectrum in which extracted substances from the chicken retina are especially photosensitive. The crest wave-lengths which we have obtained in the present experiment correspond almost precisely to ones described above except the one at $630 \mathrm{~m} \mu$.

\section{Maximal absorption at $510 \mathrm{m \mu}$}

The same experimental procedures were carried out on the toad retina and the spectral absorption pre- and post-illumination, of the extract was measured. The sodium glycocholate solution employed was $2 \%$, at $p \mathrm{H} 7.2$.

The results are illustrated in fig. 4 . In the difference spectrum there is a single high absorption maximum at about $510 \mathrm{~m} \mu$. It is clear that the visual purple is responsible at this maximum. As previously described, the absorption maximum at this wavelength can be depressed by prolonged light adaptation of the animals. Visual purple has been advocated by some that it is more photosensitive than the cone substance. From these findings, the crest at $510 \mathrm{~m} \mu$ in the difference spectrum in the chicken may be supposed to be due to the rod substance in the chicken retina.

Thus, the height of the absorption maximum of the visual purple is variable in animals according to the degrees of brightness in which they are fed. This suggests that the development of the photosensitive substance in the chicken retinae after hatching, particularly of the rod substance, might be affected by the environmental brightness. To confirm this suggestion another experiment was made.

\section{The problem of the coloured} oil globules

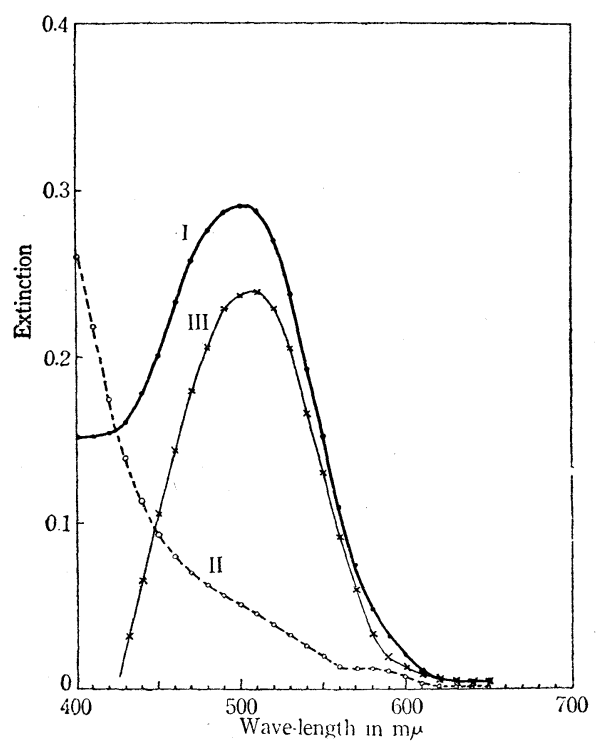

FIG. 4. Spectral absorption curve of the retinal exfract obtained from the toad with sodium glycocholate.

Curve I: before bleaching, Curve II : after bleaching with a white lamp $(200 \mathrm{~W}$, $100 \mathrm{~V})$ for 20 minutes. Curve III : absorption difference caused by bleaching.

It has long been known that there are three types of coloured oil globules in the inner cone segments of the chicken retina, the red, the yellow and bluegreen ones. Roaf (10) gave them an important place in his colour vision theory as filters absorbing part of the shorter wave-lengths in the spectrum. Can these oil globules be extracted with sodium glycocholate? And if so, to what extent? An answer to these questions is not easy. However, when the retinal residue after extraction is examined microspically, numerous oil globules are still found in the destructed cone cells as before. So, even if these globules are extracted 
with sodium glycocholate, they would not be numerous. On the other hand, Kühne (9) has found that these oil globules are very light-resistant. These facts have convinced the author that the coloured oil globules do not play an important rôle in our experiments, the chief object of which was to stress the absorption difference caused by bleaching.

\section{Humps at 420, 450 and $480 \mathrm{~m} \mu$}

The humps at 420,450 and $480 \mathrm{~m} / \ell$ which are present in the spectral absorption curve of the extract before bleaching are also observed in the curve after bleaching. Consequently, it may be concluded that the substance in these humps is not responsible to the photosensitivity of the retinal extract. From the extract obtained with

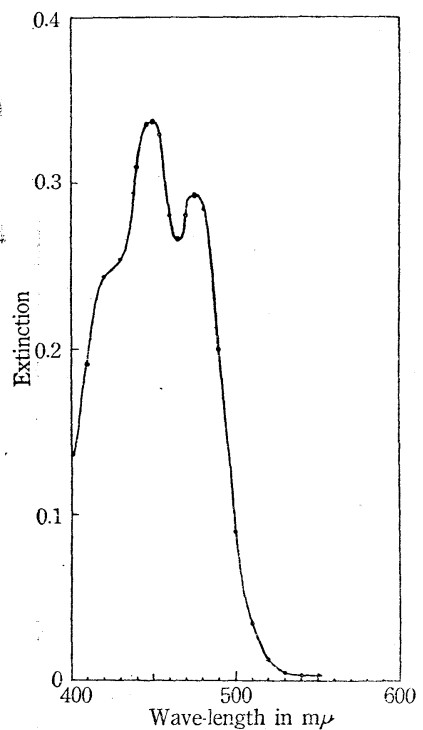

FIG. 5. Spectral absorption curve of the ethersoluble substance of the chicken retina. sodium glycocholate a yellow ether-soluble substance can be obtained. This substance indicates a typical absorption curve with three maxima at 420,450 and $475 \mathrm{~m} \mu$. In methanol the sites of these absorption maxima are invariable. In 1938 Wald and Zussman (16), dividing the benzine extract from the whole chicken retina into three fractions, found these three absorption maxima in the alcohol fractions. They declared this substance to be one contained in the yellow oil globules in the cones and identified it as xanthophyll, a carotenoid. In the light retinae and retinal pigment epithelia of frog and toad, and also in the livers of chicken, frog and toad, the same substance has been found by the author. In case of the retinal pigment epithelium of the frog or toad, possibly due to yellow oil globules named lipocrin, the maximum at $420 \mathrm{~m} \mu$ is prominently high. The existence of the substance in the liver may explain the clinical findings on impaired vision observed in some hepatic diseases. A relationship between this substance and the visual substance in sensory cells will be referred to in future.

SUMMARY

An electrophotometric experiment on a substance extracted from the chicken retina was made and the following findings were obtained.

1. A photosensitive substance in the chicken retina can be extracted with sodium glycocholate, which is usually employed for the extraction of the visual purple.

The substance is transparent reddish yellow when the procedures are carried out in dim blue-violet light.

2. This substance absorbs much of the light of shorter wave-lengths and some of the longer wave-lengths in the spectrum. 
3. The photosensitive substance extracted has five maximal absorptions ; in blue $(460 \mathrm{~m} \mu)$, blue-green $(510 \mathrm{~m} \mu)$, green $(540 \mathrm{~m} \mu)$, yellow $(570 \mathrm{~m} \mu)$ and red $(630 \mathrm{~m} \mu)$, where the crest at $510 \mathrm{~m} \mu$ is due to the visual purple.

4. When the animals are bred under continuous illumination the difference in spectrum caused by bleaching diminishes at all spectral regions, particularly at the maximum of $510 \mathrm{~m} \mu$.

5. An ether-soluble substance can be obtained from the chicken retina, the light retinae and retinal pigment epithelia of frog and toad, and also from the livers of all these animals, and its spectral absorption maxima are at 420, 450 and $475 \mathrm{~m} \mu$.

The author wishes to acknowledge his gratitude to Prof. Yuji Hosoya for suggestions and encouragement.

\section{REFERENCES}

1. Chase, A. M. Photosensitive pigments from the retina of the frog. Science $87: 238-40$, 1938.

2. Dartnall, H. J. A. New photosensitive pigments from the tench retina. Nature 166: 207-9, 1950.

3. GRAnit, R. Sensory Mechanism of the Retina. Cambridge: Oxford University Press. 1947.

4. HANSTRÖM, E. Demonstration einer Absorptionskurve des Farbstoffes in der Leichenmacula vom Affen (Macacus). Acta Ophthal. 18: 21-37, 1940.

5. Hartridge, H. Colour vision. Proc. Physiol. Soc. November 4th, 1950.

6. HESS, C. Untersuchungen über das Sehen und über die Pupillenreaktion von Tage- und Nachtvogeln. Arch. f. Augenheilk. 59: 143, 1908.

7. Hosoya, Y., OKITA, T. AND AKUne, T. Über die lichtempfindliche Substanz in der Zapfennetzhaut. Tohoku J. exp. Med. 34: 532-41, 1938.

8. Hosoy A, Y. unpublished data.

9. KÜHNE, W. Über lichtbeständige Farben der Netzhaut. Unters. Physiol. Inst. Heidelb. $1: 341-69,1878$.

10. RoAf, H. E. Colour vision. Physiol. Rev. $13: 43-79,1933$.

11. v. Studnitz, G., Über die Lichtabsorption der Retina und die photosensiblen Substanzen der Stäbchen und Zapfen. Pflïg. Arch. ges. Physiol. 230: 614-38, 1932.

12. v. Studnitz, G. Weitere Studien an der Zapfensubstanz. Pflüg. Arch. ges. Physiol. 239: $515-25,1937$.

13. v. Studnitz, G. Das Absorptionsspectrum der Zapfensubstanz. Z. vergl. Physiol. 28 : 153-64, 1940.

14. v. StudnitZ, G. AND Busch, L. Zur Chemie der Ölkugeln. Z. vergl. Physiol. $28: 638-47$, 1941.

15. WALD, G. Photolabile pigments of the chicken retina. Nature 140:545, 1937.

16. WALD, G. AND ZuSSMAN, H. Carotenoids of the chicken retina. J. biol. Chem. 122: 449-60, 1938.

\section{ADDENDUM}

In a paper, not available in this country at the time of writing, Bliss, 1946 (J. Gen. Physiol. 29: 277), reports that, in an extract of chicken retina, the bleaching effectiveness spectrum was found to be maximal at $560 \mathrm{~m} \mu$. 